\title{
A Novel Digital Approach for Forced Eruption
}

\author{
Changmin Ju, DMD, MSD', Younghoo Lee, DDS, MSD², Seoung-jin Hong, DMD, MSD, PhD², \\ Kwantae Noh, DMD, MSD, PhD³ , Janghyun Paek, DMD, MS, PhD ${ }^{3 *}$ \\ ${ }^{1}$ Graduate Student, Department of Prosthodontics, Graduate School, Kyung Hee University, Seoul, Korea \\ ${ }^{2}$ Fellow, Department of Prosthodontics, Kyung Hee University Dental Hospital, Kyung Hee University, Seoul, \\ Korea \\ ${ }^{3}$ Associate Professor, Department of Prosthodontics, School of Dentistry, Kyung Hee University, Seoul, Korea \\ *Corresponding author: Janghyun Paek, Department of Prosthodontics, School of Dentistry, Kyung Hee \\ University, Seoul, Korea. \\ Tel:+82-02-958-9340. E-mail : paek217@gmail.com
}

OPEN ACCESS

pISSN $1229-5418$

eISSN 2671-6623

Implantology 2020; 24(4): 219-225

https://oi.org/10.32542/implantology.202020

Received: October 12, 2020

Revised: December 7, 2020

Accepted: December 22, 2020

ORCID

Changmin Ju

https://orcid.org/0000-0002-9771-8398

Younghoo Lee

https://orcid.org/0000-0001-8657-159X

Seoung-jin Hong

https://orcid.org/0000-0002-7460-8487

Kwantae Noh

https://orcid.org/0000-0003-3480-7737

Janghyun Paek

https://orcid.org/0000-0002-1286-3140

Copyright $($ 2020. The Korean Academy of Oral \& Maxillofacial Implantology

\footnotetext{
This is an Open Access article distributed under the terms of the Creative Commons Attribution Non-Commercial License (http://creativecommons. org/licenses/by-nc/4.0/) which permits unrestricted non-commercial use, distribution, and reproduction in any medium, provided the original work is properly cited.
}

\section{Abstract}

Forced eruption has been proposed to expose subgingival carious lesion and achieve the biologic width when treating a tooth with subgingival dental caries. The aim of this report was to propose a new digital approach of orthodontic forced eruption. By using CAD program, orthodontic forced eruption could be planned 3-dimensionally. Using an adjacent implant as an absolute anchor, orthodontic bracket and wire were not needed.

Keywords: CAD/CAM, Digital planning, Forced eruption, Implant, Orthodontic extrusion

\section{I . Introduction}

This case report describes the orthodontic forced eruption for a permanent canine with a subgingival recurrent dental caries. The various techniques were proposed for this situation. ${ }^{1}$ Various treatment options are illustrated in Figs. 1 and 2 . The patient's economic condition was not enough for implant supported prosthesis, preserving root was chosen. Bone reduction is needed for crown lengthening procedure. Therefore, crown lengthening procedure is not desirable for implantation for future condition (i.e. after extraction of the crown lengthened tooth). Thus, orthodontic forced eruption was chosen.

Clinical value of orthodontic forced eruption has been supported by many reports. ${ }^{2-13}$

Forced eruption of the root affects the periodontal fibers. This leads a coronal shift of the marginal gingiva and the supporting bone. ${ }^{2}$ The treatment goal is to expose subgingival caries and maintain biologic width to allow restoration without causing periodontal complications. $^{14,15}$ 


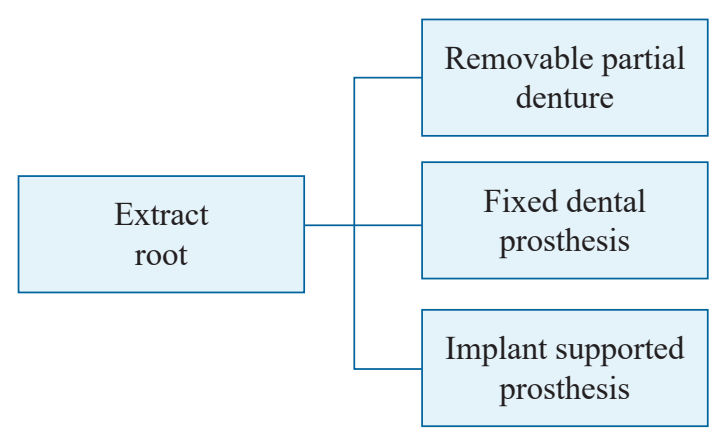

Fig. 1. Treatment options with extraction of the root.

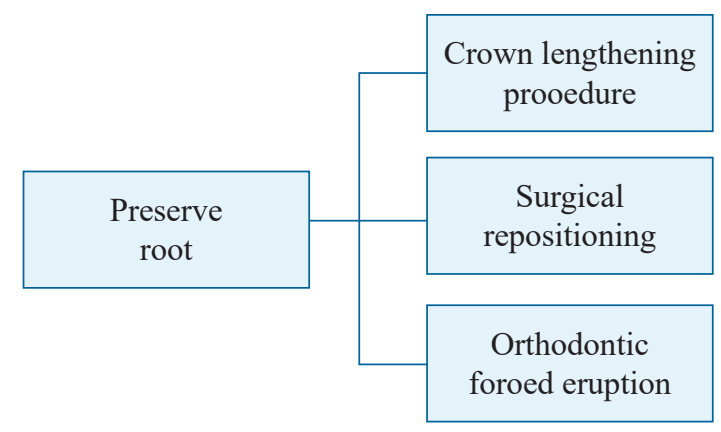

Fig. 2. Treatment options with preservation of the root.

\section{II . Case Report}

A 69-year-old female patient presented for periodic check. (Fig. 3). The results of the extraoral evaluation were unremarkable.

The intraoral evaluation revealed recurrent caries of maxillary left canine in the existing prosthesis. The tooth had extensive carious lesion. A periapical radiograph of the maxillary left canine (Fig. 4) showed recurrent caries under the fixed dental prosthesis.

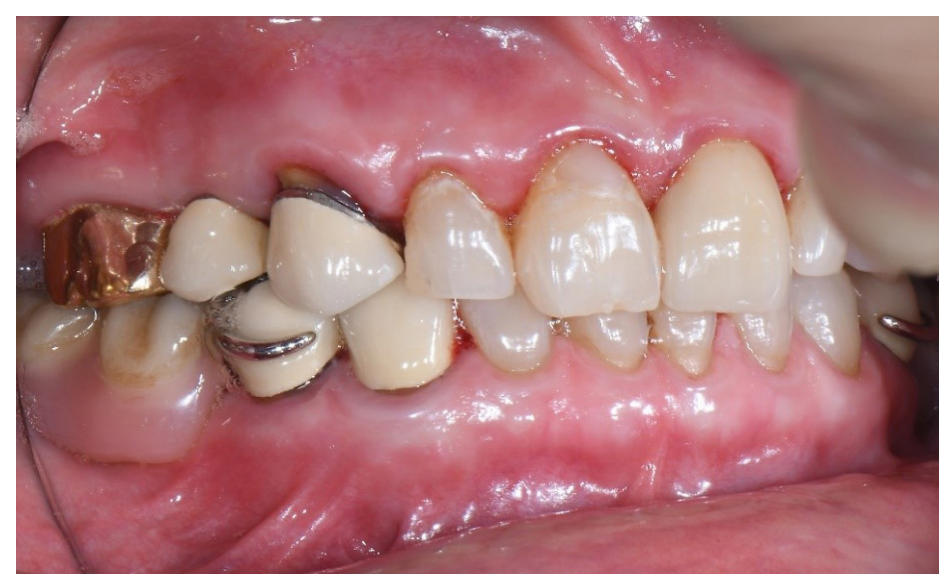

Fig. 3. Pre-operative intraoral photograph. 


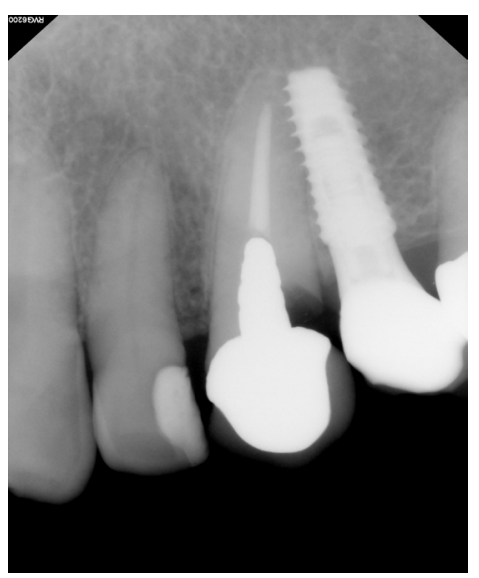

Fig. 4. Pre-operative periapical radiograph.

After dental prophylaxis and oral hygiene education, the fixed dental prosthesis and cast custom post were removed. (Fig 5). For forced eruption, the hook was inserted into the root of canine and cemented with Zinc Phosphate Cement (Elite cement, GC, Japan) (Fig 6).

Differently from other cases, the forced eruption was planned with CAD program (Exocad, Align Technology, CA) (Figs. 7 and 8). The implant supported appliance for forced eruption was designed as

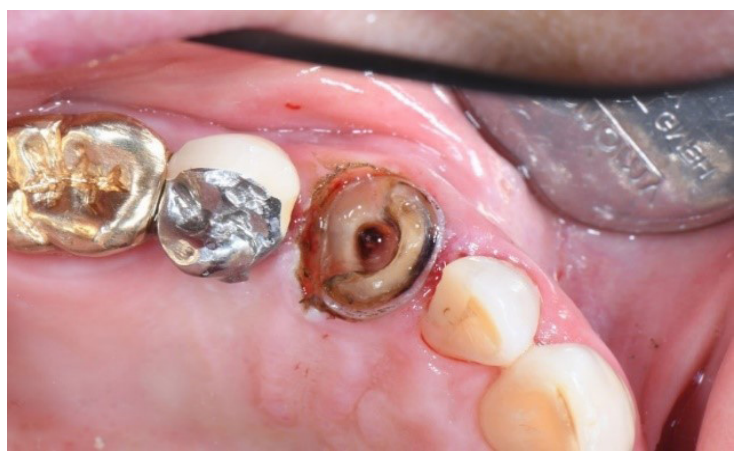

Fig. 5. Intraoral photograph after removal of cast custom post

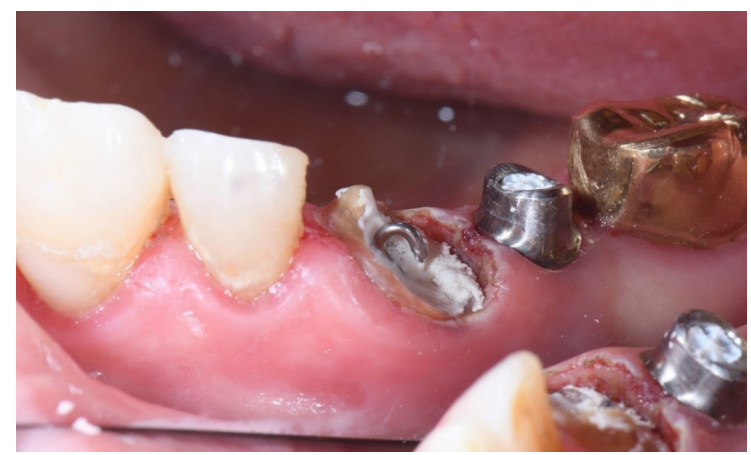

Fig. 6. Intraoral photograph of the hook. 
following. The direction of force applied to the root was designed corresponding with tooth axis. The distance between the root and the appliance was designed as $5.5 \mathrm{~mm}$. Because of the ferrule effect and biological width, the amount of eruption of $4 \mathrm{~mm}$ was needed. Considering orthodontic relapse, the overcorrection was planned as $5.5 \mathrm{~mm}$. And corresponding prosthesis was designed. The appliance was fabricated with 3D printing resin (Temporary resin, Dentis, Korea) and 3D printer (Zenith, Dentis, Korea). The hook was attached by 3D printing resin (Temporary resin, Dentis, Korea). And the appliance was cemented using RMGI cement (Fujicem, GC, Japan). Between the tooth and appliance, the power chain was engaged. As the forced eruption appliance is supported by the adjacent implant, the orthodontic bracket and wire were not needed (Figs. 9 and 10). The adjacent implant was served as an absolute anchor.

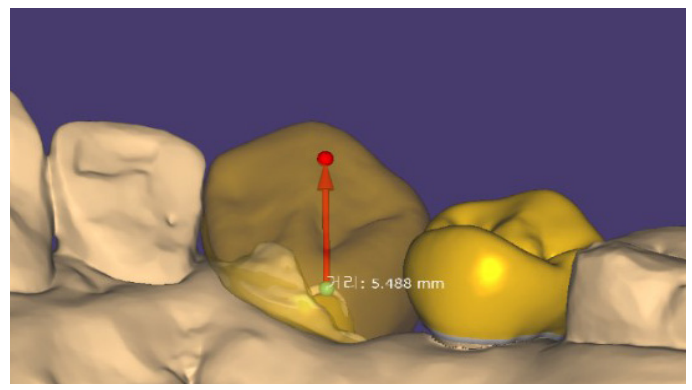

Fig. 7. Forced eruption planning in CAD program (lateral view).

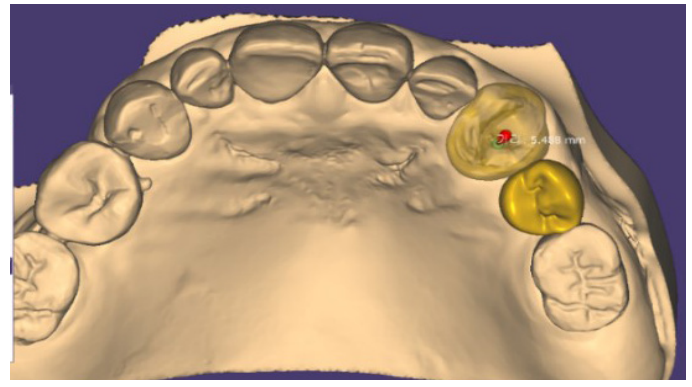

Fig. 8. Forced eruption planning in CAD program (occlusal view).

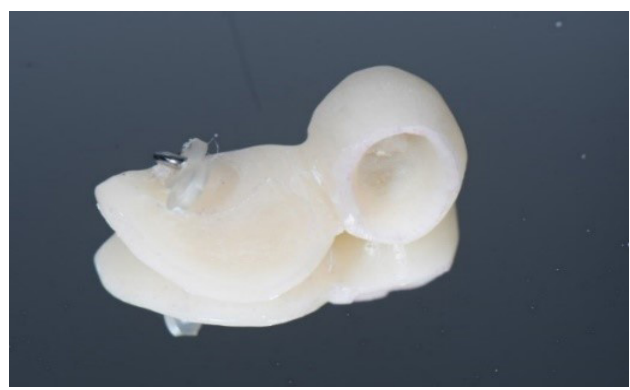

Fig. 9. Implant supported appliance for forced eruption - a hook and elastic was attached. 
Oral hygiene instructions were provided about the use of an interproximal brush in this area. Figs 10 and 11 show the delivery of forced eruption appliance.

After 2 months, the extrusive movement was completed. Figs. 12 and 13 show the post-operative state of the dentition when forced eruption was completed. After 6 weeks of period, the reorganization of the periodontal tissue around the root was successfully achieved (Fig. 14).

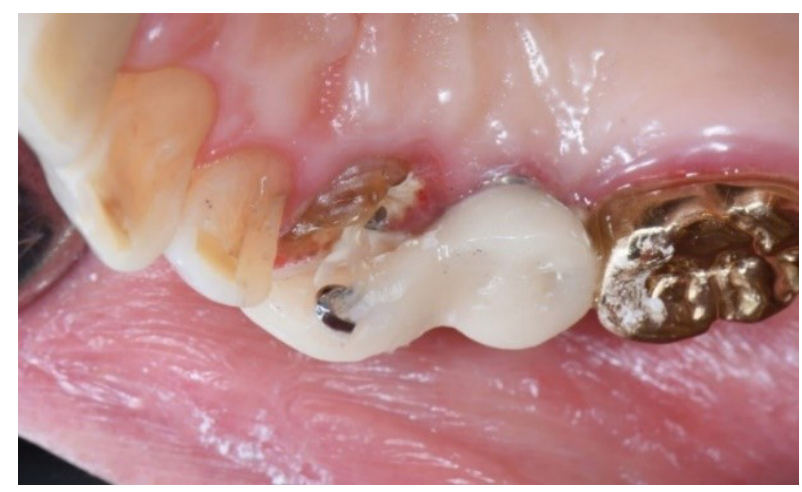

Fig. 10. Implant supported appliance for forced eruption was delivered.

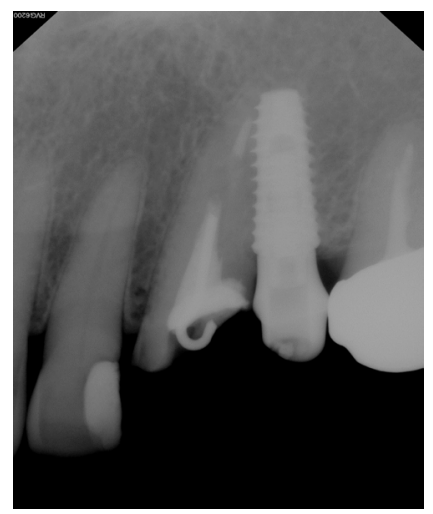

Fig. 11. Periapical radiograph at the delivery of appliance.

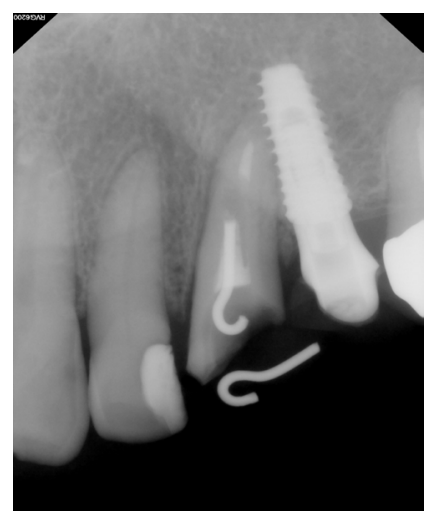

Fig. 12. Periapical radiograph upon completion of forced eruption. 


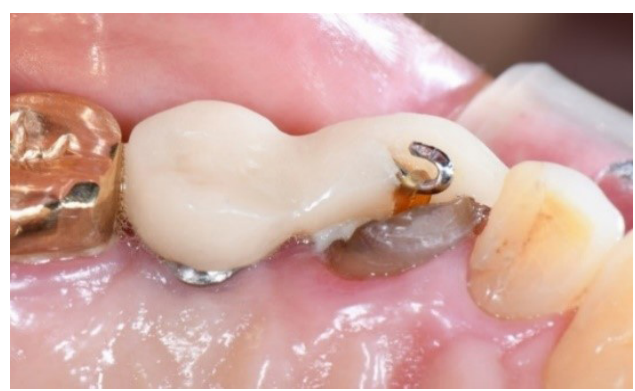

Fig. 13. Post-operative view of forced eruption.

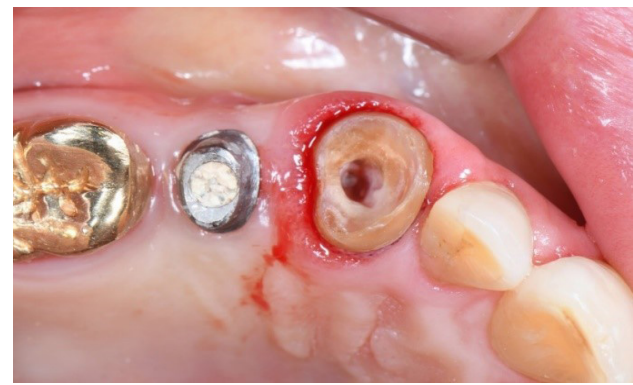

Fig. 14. After consolidation period, appliance was removed.

\section{III . Discussion}

When orthodontic forced eruption was performed, plaque retention could be increased. Thus, oral hygiene plays a key role in the orthodontic forced eruption. ${ }^{1}$ Despite of tooth brushing instruction, the additional dental caries was generated compared with initial state. A possibility can be proposed that the barrier around the elastic and appliance could make the oral hygiene poor. This appliance has a buccal wall for the esthetics, so the plaque could not be removed easily. To improve this, the buccal wall could be removed to get a good oral hygiene.

The amount of extrusion was calculated by considering the "biologic width."14 It was approximately $4 \mathrm{~mm}$. After the extrusion, the tooth still retained a crown-root ratio of approximately 1:1. It is favorable for maintaining periodontal support. Compromised crown to root ratio of 1:1 did not have the negative effect to tooth mobility due to interposition of connective tissue.

After 6 weeks period, the height and width was stabilized. And cast post and PFZ crown was delivered.

Different from the conventional method using orthodontic bracket and wire, this technique used implant supported fixed dental prosthesis as absolute anchor. Without the need of orthodontic bracket and wire esthetics and comfortable processes could be achieved by utilizing an implant as an absolute anchor. $\mathrm{CAD}$ program enables the clinician to manipulate the angle and direction of forced eruption in the most appropriate way. 


\section{Conclusion}

In this novel approach, the direction and amount of eruption were cautiously planned in CAD program, thus minimizing undesirable eruption force. Also, improved esthetics could be achieved without the wire attached to adjacent teeth comparing conventional method.

\section{References}

1. Zyskind K, Zyskind D, Soskolne WA, Harary D. Orthodontic forced eruption: case report of an alternative treatment for subgingivally fractured young permanent incisors. Quintessence Int 1992;23:393-9.

2. Ingber JSL Forced eruption. Part II. A method of treating nonrestorable teeth: periodontal and restorative considerations. J Periodontol 1976;7:203-16.

3. Simon JHS, Kelly WH, Gordon DG, Ericksen GW. Extrusion of endodontically treated teeth. J Am Dent Assoc 1978;97:17-23.

4. Delivanis P, Delivanis H, Kuftinee MM. Endodontic orthodontic management of fractured anterior teeth. J Am Dent Assoc 1978;97:483-5.

5. Shiloah J. Clinical crown lengthening by vertical root movement. J Prosthet Dent 1981;45:602-5.

6. Cronin RJ, Wardle WL. Prosthodontic management of vertical root extrusion. J Prosthet Dent 1981;46:498-504.

7. Mandel RC, Binzer WC, Withers JA. Forced eruption in restoring severely fractured teeth using removable orthodontic appliances. J Prosthet Dent 1982;47:269-74.

8. Bielak S, Bimstein E, Eidelman E. Forced eruption: the treatment of choice for subgingivally fractured permanent incisors. ASDC J Dent Child 1982;49:186-90.

9. Lemon RR. Simplified esthetic root extrusion techniques. Oral Surg Oral Med Oral Pathol 1982;54:93-9.

10. Johnson GK, Sivers JE. Forced eruption in crown-lengthening procedures. J Prosthet Dent 1986;56:424-7.

11. Emerich-Poplatek K, Sawicki L, Bodal M, Adamowicz-Klepalska B. Forced eruption after crown/ root fracture with a simple and aesthetic method using the fractured crown. Dent Traumatol 2005;21:165-9.

12. Bach N, Baylard JF, Voyer R. Orthodontic extrusion: periodontal considerations and applications. J Can Dent Assoc 2004;70:775-80.

13. Canjau S, Stefan C, Szuhanek CA. Alternative treatment approach for anterior subgingival dental lesions: Forced eruption using attractive magnets. Am J Orthod Dentofacial Orthop 2020;158:126-33.

14. Ingber JS, Rose LF, Coslet JG. The "biologic width" - a concept in periodontics and restorative dentistry. Alpha Omegan 1977;10:62-5.

15. Stern N, Becker A. Forced eruption: biological and clinical considerations. JOral Rehabil 1980;7:395402. 